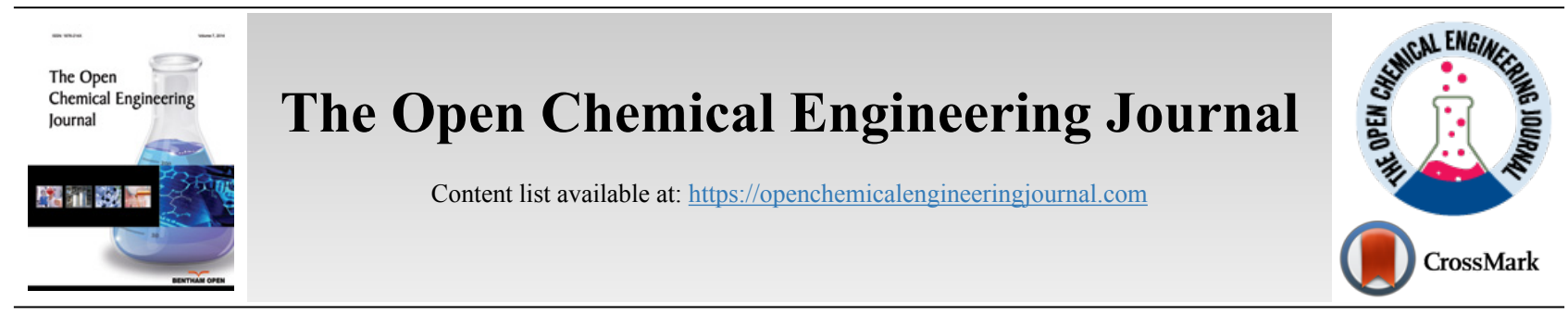

RESEARCH ARTICLE

\title{
Electrochemical Polymerised Graphene Paste Electrode and Application to Catechol Sensing
}

Jamballi G. Manjunatha*

Department of Chemistry, FMKMC College, Madikeri, Mangalore University Constituent College, Karnataka, India

\begin{abstract}
:
Objective:

To build up an advantageous strategy for sensitive determination of catechol (CC), a poly (proline) modified graphene paste electrode (PPMGPE) was fabricated and used as a voltammetric sensor for the determination of CC.

Methods:

The performance of the modified electrode was studied using cyclic voltammetric (CV) and differential pulse voltammetric method (DPV). The modified electrode was characterized by CV and DPV. The surface of the modified electrode was examined by FESEM. The electrochemical behavior of $\mathrm{CC}$ in phosphate buffer solution ( $\mathrm{pH} 7.5)$ was inspected using bare graphene paste electrode (BGPE) and PPMGPE.

Results \& Conclusion:

The PPMGPE shows a lower limit of detection, calculated to be $8.7 \times 10^{-7} \mathrm{~mol} \mathrm{~L}^{-1}(\mathrm{~S} / \mathrm{N}=3)$. This modified electrode was applied successfully for the determination of $\mathrm{CC}$ in water samples without applying any sample pretreatment.
\end{abstract}

Keywords: Poly (proline) modified graphene paste electrode, Catechol, Cyclic voltammetry, Water sample analysis, Detection limit.

\begin{tabular}{|l|l|l|l} 
Article History & Received: April 12,2019 & Revised: May 28, 2019 & Accepted: June 12, 2019
\end{tabular}

\section{INTRODUCTION}

Graphene paste electrode was particularly used for the determination of bioactive molecules because of the easy fabrication of polymer modified electrode, reclaimable and good response and less background current $[1-8]$. Very few modified electrodes were fabricated by using graphene paste, polymer and surfactants for the analysis of CC by using voltammetric techniques. Catechol is an environmental pollutant which affects the human nervous system and difficult to be degraded in the ecological environment [9 - 13]. Henceforth, determination of $\mathrm{CC}$ from compost bioremediation of municipal solid waste is a basic issue. Moreover, with the enhancement of the requirement for environmental quality, there should be a set of fast and adequate detection technique. In this way, it is important to build up a fast, simple and sensitive way to detect $\mathrm{CC}$. These days, there are some unique approaches to identify CC, including chromatography [14, 15], fluorescence [16], spectrophotometry [17, 21], chemiluminescence [18] and electrochemical method [19, 20]. Tragically, most of them hold the requirements of the expensive instru

* Address correspondence to this author at the Department of Chemistry, FMKMC College, Madikeri, Mangalore University Constituent College, Karnataka, India; Tel: +91- 08272228334; E-mail: manju1853@gmail.com -ments and the sample pretreatment, which have the imperfections of the large expense and long time. The technique to polymerization is one of the key issues in developing a reliable biosensor. Polymer modified electrodes have received a great deal of attention as an electrode material because it shows some fascinating properties with regards to the electrochemical investigation [22]. Polymer modified electrodes have been widely applied in the field of electrochemistry attributable to their good stability, permselectivity, novel physical and chemical properties [23]. Studies have demonstrated that polymer modified electrodes show an improved response for the determination of different biological and clinical molecules [24]. Proline can be easily electro-polymerized on the electrode surface to form poly (proline) film. Polymerization film has been utilized in bunches of oxidation and reduction catalytic processes [25 - 27]. The electrochemical polymerization in different ratios on glassy carbon electrode by cyclic potential sweep has been reported by Yongjun et al. [28]. Polymer modification for enhancing the analytical sensitivity owing to high electron density, dielectric property, catalytic function and incredible biocompatibility [26 - 29].

Our research team has made progress in researching 
polymer modified graphene paste electrodes. In this paper, the fabrication of a graphene-based polymer modified biosensor for the determination of $\mathrm{CC}$ was portrayed. The polymer modification was performed using cyclic voltammetry from an acidic solution containing appropriate concentrations of monomer and buffer. The polymer modified electrode could remarkably enhance the electrochemical responses of $\mathrm{CC}$ and improve the sensitivity of $\mathrm{CC}$ detection and its oxidation mechanism (Fig. 1) [35]. Moreover, the electrochemical sensor was effectively utilized to determine the $\mathrm{CC}$ concentration in the real sample.<smiles>Oc1ccccc1O</smiles>

Catechol<smiles></smiles>

1,2 Benzoquinone
Fig. (1). The scheme of oxidation of CC.

\section{MATERIALS AND METHODS}

\subsection{Reagents and Apparatus}

Chemicals and reagents utilized in this work were of analytical grade and were used as received. These were Catechol (SRL, Maharashtra), silicone oil, disodium hydrogen phosphate, monosodium di hydrogen phosphate and SDS obtained from Himedia chemicals, India and were used as received. Graphene (6-8 $\mathrm{nm}$ thickness, five $\mu \mathrm{M}$ wide) was obtained from TCI Co. restricted (Japan). Phosphate buffer solution (PBS) was prepared by a combination of an appropriate quantity of NaH2PO4/ Na2HPO4. The stock solution of $\mathrm{CC}\left(25 \times 10^{-4} \mathrm{M}\right)$, proline $\left(25 \times 10^{-3} \mathrm{M}\right)$ were prepared in the double distilled water. All the solutions were prepared by double distilled water.

Voltammetric investigations were carried out on a CHI 6038E electrochemical workstation (USA). All measurements were conducted in a three-electrode cell with a platinum wire as an auxiliary electrode and a saturated calomel electrode (SCE) as a reference electrode. The working electrode was the homemade graphene paste electrode with a diameter of $3 \mathrm{~mm}$ modified with poly (proline) film.

\subsection{Preparation of the Working Electrodes}

The Graphene paste electrode (GPE) was obtained by homogeneous mixing of graphene with silicone oil in a mortar and pestle at a ratio of $60 / 40(\mathrm{w} / \mathrm{w})$. The paste was then inserted into the electrode cavity $(3 \mathrm{~mm})$ and electrical contact was made by means of copper wire. BGPE surface was smoothed on a tissue paper. Tests were performed in $0.1 \mathrm{M}$ PBS of $\mathrm{pH} 7.5$ with various concentrations of CC.

Electrochemical polymerization of Proline is carried out potentiodynamically in the potential window from $-0.6 \mathrm{~V}$ to $+1.2 \mathrm{~V}$ for 10 cycles (Fig. 2). While the polymerization process is well-known, the number of cycles and the concentration of proline have been optimized. After polymerization, the electrodes were washed repeatedly with distilled water. Polymerised electrode works as the working electrode for the electrochemical detection of $\mathrm{CC}$.

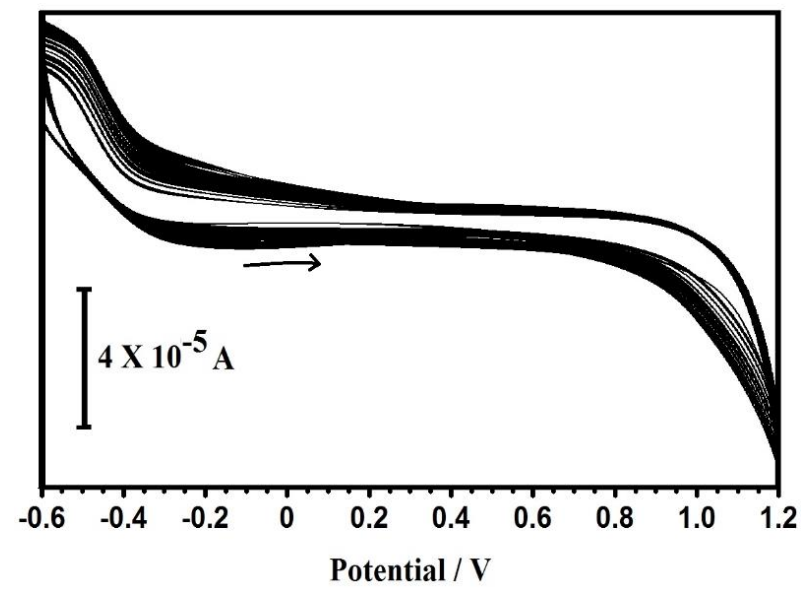

Fig. (2). Successive continuous ten cyclic voltammograms for the electrochemical polymerization of $1 \times 10^{-3} \mathrm{M}$ proline on a BGPE in 0.1 M M PBS (7.5pH) at the scan rate $100 \mathrm{mV} / \mathrm{s}$.

\subsection{Electrochemical Measurements}

$\mathrm{CC}$ analysis was achieved in a glass cell with a threeelectrode configuration. The experiments involving cyclic voltammetry and differential pulse voltammetry (DPV) were performed in the potential range from $-0.2 \mathrm{~V}$ to $0.6 \mathrm{~V}$ and -0.2 $\mathrm{V}$ to $0.40 \mathrm{~V}$, respectively. All the experiments were carried out at the room temperature.

\section{RESULTS AND DISCUSSION}

\subsection{Morphological Characterization of BGPE and PGMCPE}

The surface morphology of BGPE and PPMGPE was determined by FESEM. Fig. (3) indicates that there are obvious differences between the two electrodes. Morphology of the (a) BGPE and (b) PPMGPE is shown in Figs. (3a) and (b), respectively. Generation of a thin layer on the GPE surface can be proved by the deposited proline clusters on the surface.

\subsection{Cyclic Voltammetric Detection of CC at PPMGPE}

Fig. (4) shows the cyclic voltammetric responses at BGPE and PPMGPE in 0.1 M PBS solution ( $\mathrm{pH} 7.5$ ) containing 0.1 $\mathrm{mM} \mathrm{CC}$. At the BGPE, CC (Fig. 4) $0.1 \mathrm{mM}$ reversible electrochemical behaviors with relatively weak redox currents. The CV of PPMGPE shows well-defined anodic and cathodic peaks at $0.112 \mathrm{~V}$ and $0.036 \mathrm{~V}$, respectively, with an enhanced current response due to the good catalysis of PPMGPE for CC oxidation. The total peak current for the oxidation of $\mathrm{CC}$ at the PPMGPE is about $178 \%$ higher. In comparison to the BGPE, the electrochemical reaction of CC at the PPMGPE shows an outstanding enhancement. In the oxidation peak, reduction peak potential separations of the CC significantly narrowed.

Investigation of $\mathrm{CC}$ was done by applying the DPV 
technique at BGPE and PPMGPE in $0.1 \mathrm{M}$ PBS ( $\mathrm{pH}$ 7.5) solution containing $0.1 \mathrm{mM} \mathrm{CC}$. As shown in Fig. (5), at the BGPE, the electrooxidation of $\mathrm{CC}$ molecules presented weak peaks as the determination of the $\mathrm{CC}$ molecules is very diffi-

(A)

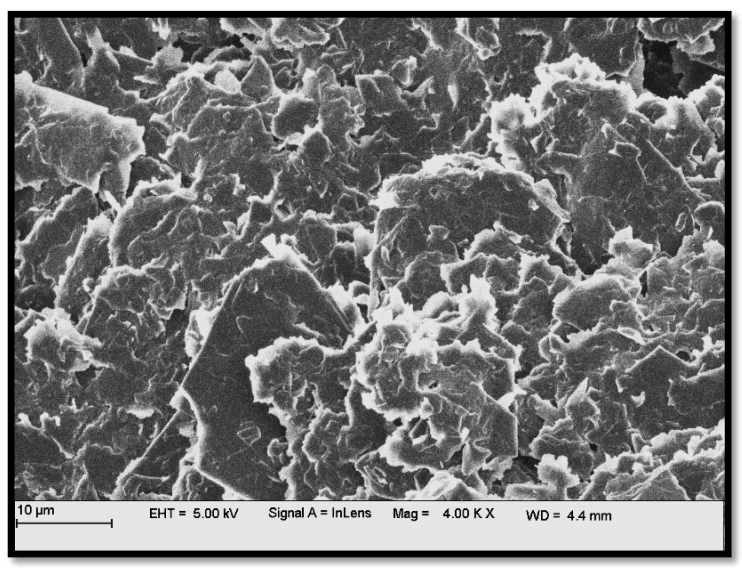

(B)

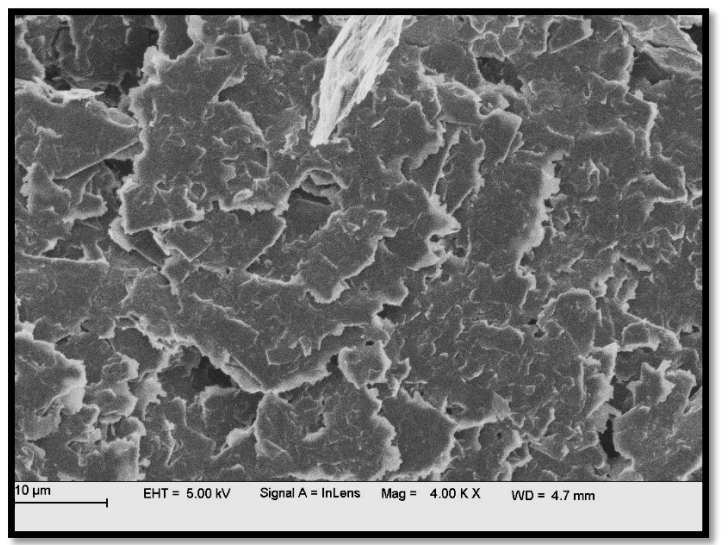

Fig. (3). FESEM image of (a) BGPE (b) PPMGPE.

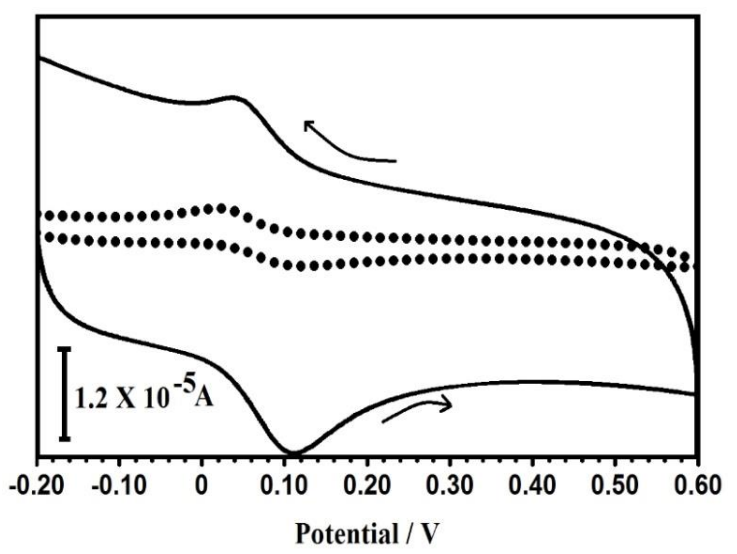

Fig. (4). (a) cyclic voltammograms of $\mathrm{CC}\left(1 \times 10^{-4} \mathrm{M}\right)$ in $0.1 \mathrm{M}$ phosphate buffer solution of $\mathrm{pH} 7.5$ at BGPE (dotted line) and PPMGPE (solid line).

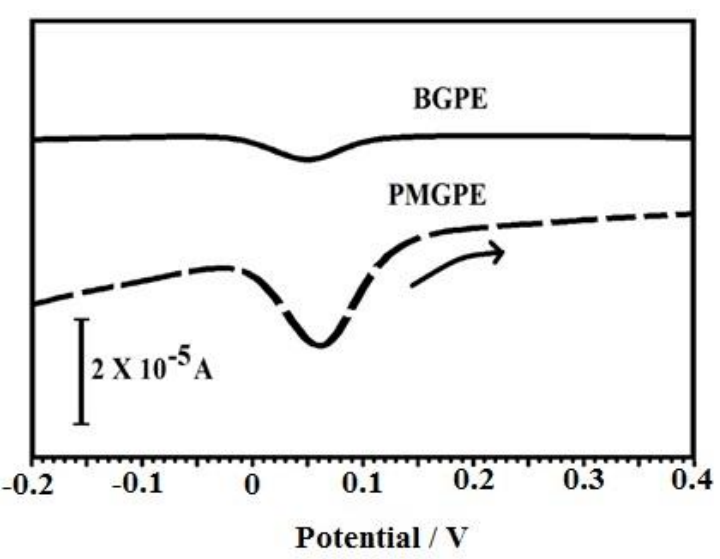

Fig. (5). DPVs of a solution containing CC $\left(1 \times 10^{-4} \mathrm{M}\right)$ in $0.1 \mathrm{M}$ PBS $(\mathrm{pH} 7.5)$ at the BGPE (solid line), the PPMGPE (dashed line).

cult. In contrast, at the PPMGPE, well-defined oxidation peaks were observed at $0.06 \mathrm{~V}$ and higher (approximately 7.2 times) oxidation peak currents appeared.

Comparing the voltammetric peaks of PPMGPE in the presence and absence of $0.1 \mathrm{mM} \mathrm{CC}$, in $0.1 \mathrm{M}$ PBS solution, at a scan rate $100 \mathrm{mVs}^{-1}$ (Fig. 6), it is revealed that the observed peak is exclusively due to the oxidation of $\mathrm{CC}$ and there was no redox peak of PPMGPE in the blank solution. From these measurements, it can be concluded that the background current of the buffer (supporting electrolyte) has no interrupting signal at the time of the electrochemical determinations on the PPMGPE in the potential window between $-0.2 \mathrm{~V}$ and $0.6 \mathrm{~V}$.

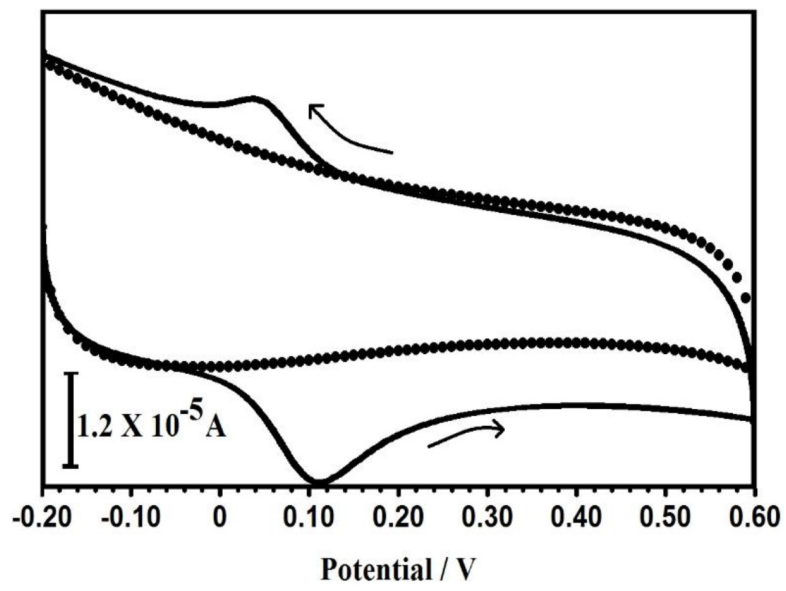

Fig. (6). A typical cyclic voltammograms of PPMGPE with CC $\left(1 \times 10^{-4}\right.$ M) (solid line) in $\mathrm{pH} 7.5 \mathrm{PBS}$ without $1 \times 10^{-4} \mathrm{M} \mathrm{CC}$ (dotted line) at $\mathrm{pH}$ 7.5 PBS.

\subsection{Measurement of Repeatability, Reproducibility and Stability}

The repeatability and reproducibility of the PPMGPE sensor for the determination of $\mathrm{CC}$ have been analysed by the $\mathrm{CV}$ studies. CVs were recorded in $\mathrm{pH}$ 7. 5 PBS at the scan rate of $100 \mathrm{mV} / \mathrm{s}$ in the presence of CC at $0.1 \mathrm{mM}$. The modified 
sensor indicates excellent repeatability with a relative standard deviation (R.S.D.) of $3.8 \%$ for $(n=4)$ continuous measurements. Moreover, it shows an agreeable reproducibility with an R.S.D. of $2.3 \%$ for 3 distinctive determinations.

Stability of the PPMGPE has been evaluated by storing it at the closed vessel. It has been stable for seven days and after that, a gradual decrease $(6 \%)$ was observed from the current initial value. These values indicate that the modified film was electrochemically active and retain good stability.

\subsection{The Effect of Solution $\mathrm{pH}$}

The effect of solution $\mathrm{pH}$ on the $\mathrm{CV}$ responses of $\mathrm{CC}$ using the PPMGPE was measured. As the $\mathrm{pH}$ was raised from 6 to 8.0, the oxidation peak potentials of the $\mathrm{CC}$ deviate to more negative values as shown in Fig. (7a) with linear relationship equation $\mathrm{E}_{\mathrm{pc}}$ of $\mathrm{CC}$ with $\mathrm{pH}$ and were described as Epa $(\mathrm{V})=$ $0.511-0.0631 \mathrm{pH}(\mathrm{R}=0.9977)$ (Fig. 7b). The slope (63.1 $\mathrm{mVpH}^{-1}$ ) of CC adjacent to the theoretical value of $59 \mathrm{mV} \mathrm{pH}^{-1}$, expresses that their oxidation reactions are followed by the transfer of an equal number of protons and electrons [5 - 11]. We chose 7.5 as the best $\mathrm{pH}$ for the analysis of CC, because of the higher sensitivity at this $\mathrm{pH}$ (Fig. 7c).

\subsection{The Effect of Potential Sweep Rate}

The effect of sweep rate or scan rate on the oxidation peak current and peak potential can examine the electrochemical kinetics of electrode reaction [2 - 4]. Fig. (8a) shows that the $\mathrm{CV}$ reaction at the PPMGPE with various scan rates in $0.1 \mathrm{M}$ PBS solution ( $\mathrm{pH} 7.5$ ) consists of $0.1 \mathrm{mM} \mathrm{CC}$. When the scan rate varies from $100 \mathrm{mV} / \mathrm{s}$ to $300 \mathrm{mV} / \mathrm{s}$, the oxidation peak currents of CC (Fig. 8b) increase with the changes of scan rate, while their oxidation peak potentials gradually deviate to positive values. Moreover, the relationship between oxidation peak currents and the scan rates is linear. The linear equations are expressed as follows: $I_{p a}(\mu \mathrm{A})=13.32+0.150 v\left(\mathrm{mVs}^{-1}\right)$ with correlation coefficient of $\mathrm{r}^{2}=0.9976$. The linear relationships show that the $\mathrm{CC}$ molecule was influenced by the surface adsorption-controlled process [22 - 24].

\subsection{PPMGPE Electrochemical Sensors for CC Detection}

The CV was used to prepare the calibration curve. Under the optimized conditions, the electrode response to $\mathrm{CC}$ concentrations was checked at the PPMGPE (Fig. 9). The results showed two calibration curves corresponding to two concentration range of $2 \times 10^{-6}-4.5 \times 10^{-5} \mathrm{M}$ and $5 \times 10^{-5}-1.5 \times 10^{-4}$ $\mathrm{M}$ CC. The regression equations were $\mathrm{I}_{\mathrm{pa}}(\mathrm{A})=$ $1.34 \times 10^{-5}+0.089 \mathrm{C},\left(\mathrm{r}^{2}=0.999\right)$ and $\mathrm{I}_{\mathrm{pa}}(\mathrm{A})=1.58 \times 10^{-5}+0.039 \mathrm{C}$, $\left(r^{2}=0.997\right)$, respectively. The limit of detection was obtained (according to $\mathrm{DL}=3 \mathrm{sb} / \mathrm{m}$, where $\mathrm{sb}$ is the standard deviation of the blank response and $\mathrm{m}$ is the slope of the calibration plot) [25 - 27] as $8.7 \times 10^{-7} \mathrm{M}$ and limit of quantification obtained as $4.3 \times 10^{-6} \mathrm{M}$. Detection limit for $\mathrm{CC}$ at PPMGPE is in comparison with other research publication Refs [30 - 36] while the proposed electrochemical sensor was very easier than other electrochemical sensors (Table 1).
(A)

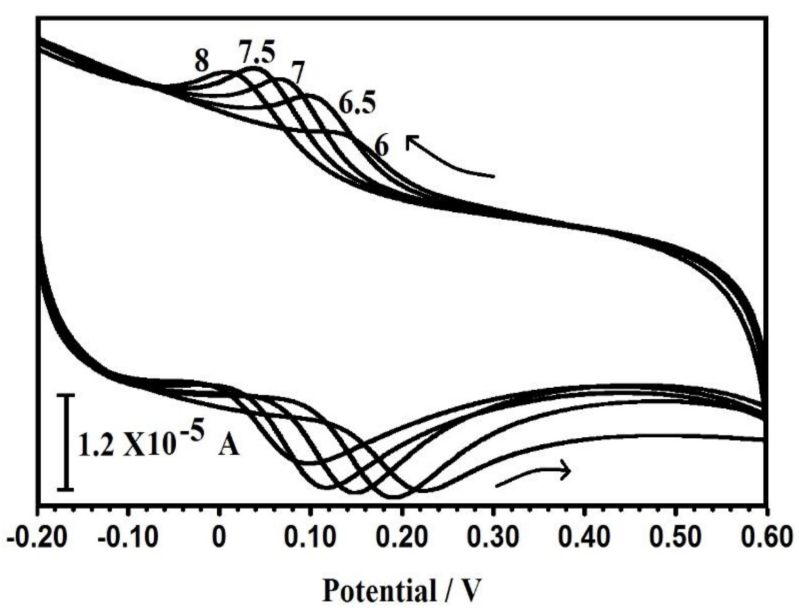

(B)

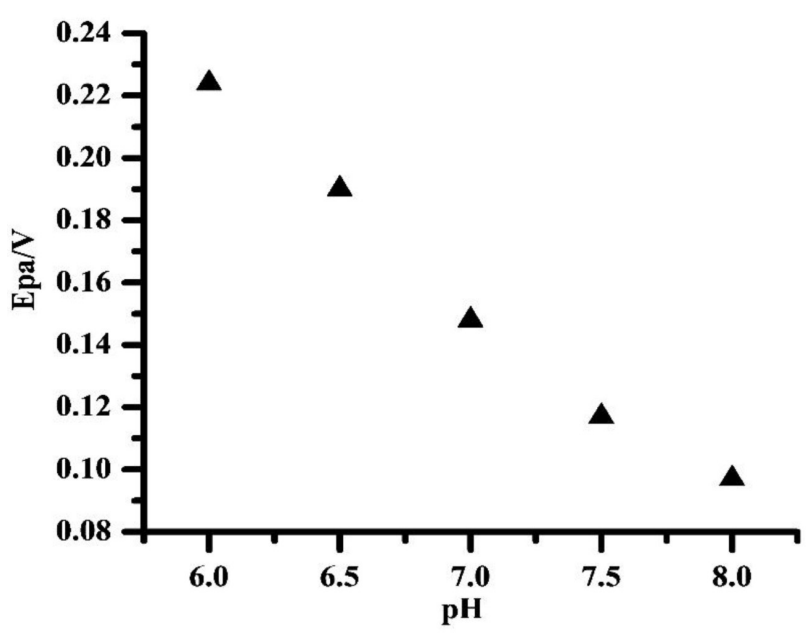

(C)

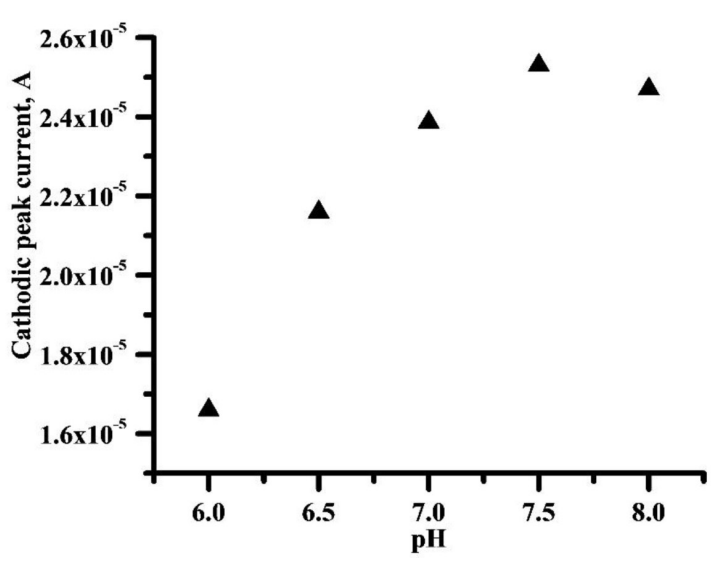

Fig. (7). (a) Cyclic voltammograms obtained at the PPMGPE in $0.1 \mathrm{M}$ PBS in pH values, (a) 5.5 (b) 6 (c) 6.5 (d) 7 (e) 7.5 (f) 8 containing CC $(1 \times 10-4 \mathrm{M})(\mathbf{b})$ Plot of anodic peak Potential vs. $\mathrm{pH}(5.5-8.0)$ of CC $(1 \times 10-4 \mathrm{M})$ at the PPMGPE (c). Plot of Ipc $v s \mathrm{pH}$ for CC. 
(A)

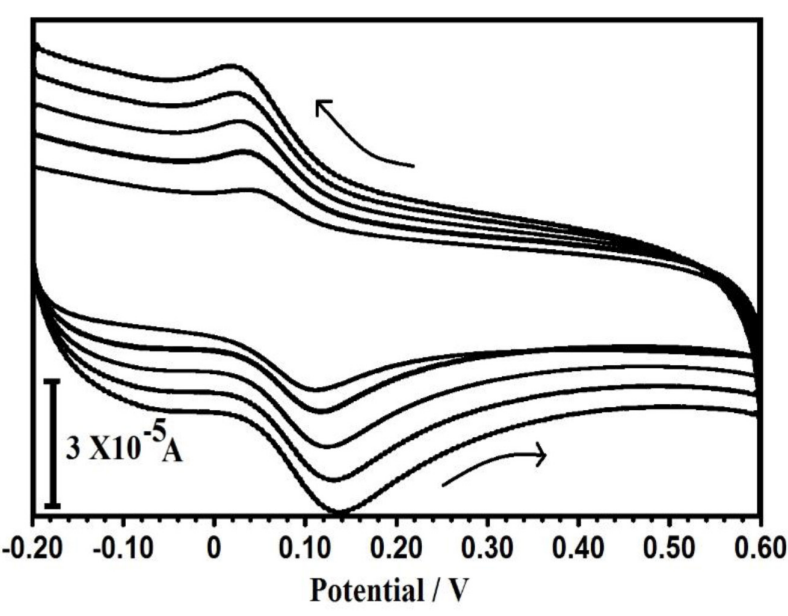

(B)

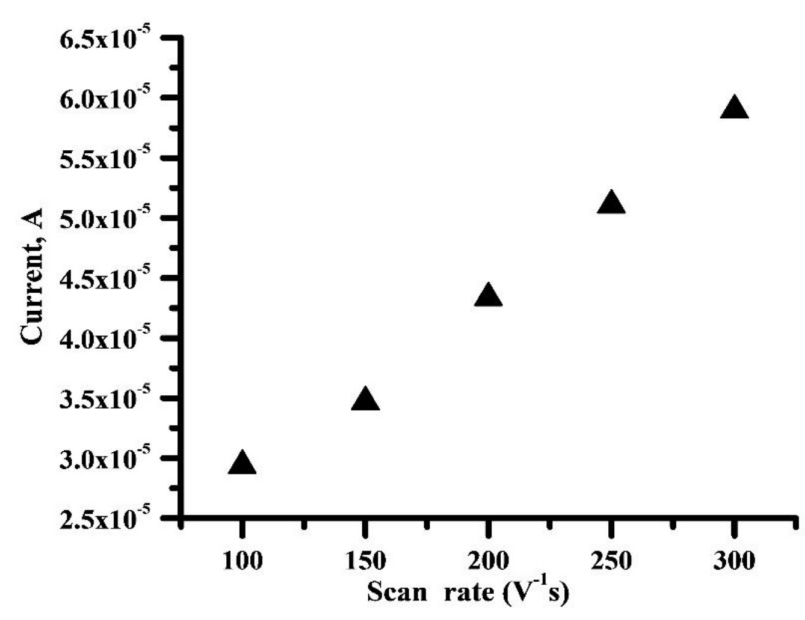

Fig. (8). (a) Cyclic voltammograms of $\mathrm{CC}\left(1 \times 10^{-4} \mathrm{M}\right)$ at the PPMGPE in $\mathrm{pH} 7.5$ PBS at various scan rates. From: 100,150, 200, 250 and 300 $\mathrm{mV} / \mathrm{s}$. (b) Plot of the peak current of CC as a function of the scan rate.

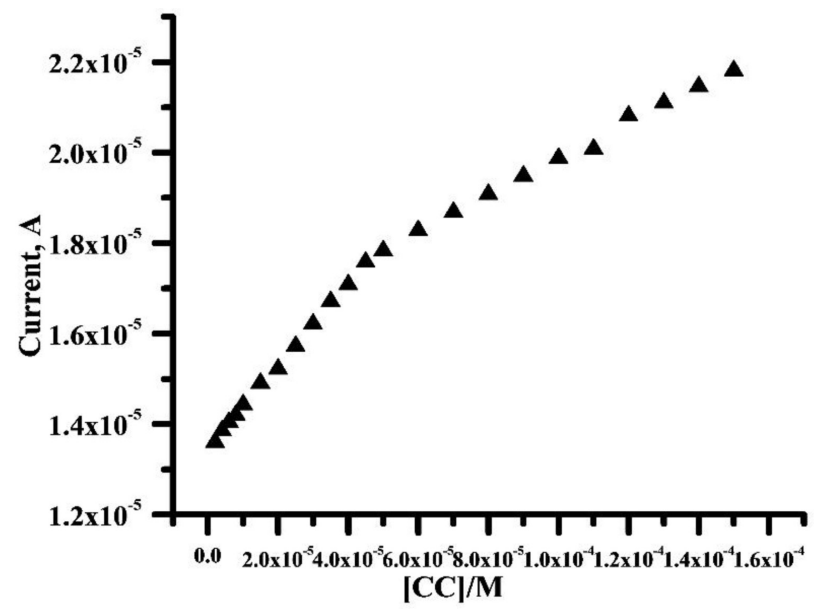

Fig. (9). Calibration plot for the determination of $\mathrm{CC}$ at the PPMGPE in $\mathrm{pH} 7.5 \mathrm{PBS}$ with the scan rate $100 \mathrm{mV} / \mathrm{s}$.

\subsection{Real Sample Analysis}

To measure the applicability of the PPMGPE in the real sample analysis, CC was used to determine it in water. The standard addition technique was applied for the determination of recoveries. Recoveries have been found to be in between 94.1-97.4\%.

Table 1. Detection limit with different methods for the determination of $\mathbf{C C}$.

\begin{tabular}{|c|c|c|c|}
\hline Working Electrode & $\begin{array}{c}\text { Limit of Dtection } \\
\text { in } \boldsymbol{\mu} \mathbf{M}\end{array}$ & Method & Reference \\
\hline $\begin{array}{c}\text { Zn/Al Layered Double } \\
\text { Hydroxide Film MGCE }\end{array}$ & 1.2 & DPV & 30 \\
\hline $\begin{array}{c}\text { Glassy carbon electrode } \\
\text { in CPB and SDBS }\end{array}$ & 3 & DPV & 31 \\
\hline Silsesquioxane-MCPE & 10 & DPV & 32 \\
\hline $\begin{array}{c}\text { Graphene oxide and } \\
\text { multiwall carbon nanotubes }\end{array}$ & 1.8 & DPV & 33 \\
\hline $\begin{array}{c}\text { [Cu(Sal- } \beta \text {-Ala)(3,5-DMPz)2] } \\
\text { /SWCNTs/GCE }\end{array}$ & 3.5 & DPV & 34 \\
\hline Poly(calmagite) MCPE & 2.55 & DPV & 35 \\
\hline $\begin{array}{c}\text { PEDOT/GO modified } \\
\text { Electrode }\end{array}$ & 1.66 & DPV & 36 \\
\hline PPMGPE & $8.7 \times 10^{-7}$ & $\mathrm{CV}$ & This work \\
\hline
\end{tabular}

\section{CONCLUSION}

In this present work, we have favorably employed an easy methodology for the electrochemical fabrication of PPMGPE. The modified electrode was analyzed by FESEM. This study shows that the prepared proline film was decorated on the electrode. The electrochemical behavior of the PPMGPE has been tested using CV and DPV methods. The PPMGPE possesses the high electroactive surface area which is well appropriate for the determination of CC. Lastly, the PPMGPE is also employed for the detection of CC in real samples. Thus, the PPMGPE exhibits higher stability, reproducibility and promising electrocatalytic activity and quick response towards the determination of $\mathrm{CC}$ in both lab and real sample analysis.

\section{CONSENT FOR PUBLICATION}

Not applicable.

\section{AVAILABILITY OF DATA AND MATERIALS \\ Not applicable.}

\section{FUNDING}

The study financially supported by We gratefully acknowledge the financial support from the VGST, Bangalore under Research Project. No. KSTePS/VGST-KFIST (L1)2016-2017/GRD-559/2017-18/126 /333, 21/11/2017.

\section{CONFLICT OF INTEREST}

The author declares no conflict of interest, financial or otherwise.

\section{ACKNOWLEDGEMENTS}

We gratefully acknowledge the financial support from the VGST, Bangalore 


\section{REFERENCES}

[1] S.Z. Mohammadi, H. Beitollahi, and H. Fadaeian, "Voltammetric Determination of isoproterenol using a Graphene Oxide Nano Sheets Paste Electrode", J. Anal. Chem., vol. 73, pp. 705-712, 2018. [http://dx.doi.org/10.1134/S1061934818070122]

[2] H. Beitollahi, S. Mohadeseh, and T. Somayeh, "Application of Graphene and Graphene Oxide for modification", Int. J. Nanodimens., vol. 10, pp. 125-140, 2019.

[3] H. Beitollahi, M. Hamzavi, and M. Torkzadeh-Mahani, "Electrochemical determination of hydrochlorothiazide and folic acid in real samples using a modified graphene oxide sheet paste electrode", Mater. Sci. Eng. C, vol. 52, pp. 297-305, 2015. [http://dx.doi.org/10.1016/j.msec.2015.03.031] [PMID: 25953571]

[4] H. Beitollahi, D. Gholamreza, M.H. Mahmoudi, and F. Hamid, "A Sensitive Electrochemical DNA Biosensor for Anticancer Drug Topotecan Based on Graphene Carbon Paste Electrode", J. Electrochem. Soc., vol. 164, pp. 812-817, 2017.

[http://dx.doi.org/10.1149/2.0511712jes]

[5] Jamballi G. Manjunatha, and M. Deraman, "Graphene paste electrode modified with sodium dodecyl sulfate surfactant for the determination of dopamine, ascorbic acid and uric acid", Anal.Bioanal.Electrochem., vol. 9, pp. 198-213, 2017.

[6] J.G. Manjunatha, "A novel voltammetric method for the enhanced detection of the food additive tartrazine using an electrochemical sensor", Heliyon, vol. 4, no. 11, 2018.e00986 [http://dx.doi.org/10.1016/j.heliyon.2018.e00986] [PMID: 30761373]

[7] Y. Beibei, W. Huiwen, D. Jiao, F. Yunzhi, Y. Ping, and D. Yukou, "Direct electrodeposition of reduced graphene oxide on carbon fiber electrode for simultaneous determination of ascorbic acid, dopamine and uric acid", Colloids Surf. A Physicochem. Eng. Asp., vol. 20, pp. 146-152, 2014.

[8] R. Muniyandi, D. Balamurugan, C. Shen-Ming, and Y. Pin-Chun, "Single step electrochemical fabrication of highly loaded palladium nanoparticles decorated chemically reduced graphene oxide and its electrocatalytic applications", Colloids Surf. A Physicochem. Eng. Asp., vol. 452, pp. 39-45, 2014.

[http://dx.doi.org/10.1016/j.colsurfa.2014.03.058]

[9] P.A. Kilmartin, and F.H. Chyong, "Characterization of polyphenols in green, oolong, and black teas, and in coffee, using cyclic voltammetry", Food Chem., vol. 82, pp. 501-512, 2003. [http://dx.doi.org/10.1016/S0308-8146(03)00066-9]

[10] Y.G. Sun, H. Cui, Y.H. Li, and X.Q. Lin, "Determination of some catechol derivatives by a flow injection electrochemiluminescent inhibition method", Talanta, vol. 53, no. 3, pp. 661-666, 2000 [http://dx.doi.org/10.1016/S0039-9140(00)00550-6] [PMID: 1896 8154]

[11] K. Abolfazl, J.B. Raoof, N. Davood, and O. Reza, "Electrochemical study of catechol in the presence of dibuthylamine and diethylamine in aqueous media: Part 1 Electrochemical investigation", Electroanal., vol. 17 , pp. $755-1760,2005$

[12] C. Wei, Q. Huang, S. Hu, H. Zhang, W. Zhang, Z. Wang, M. Zhu, P. Dai, and L. Huang, "Simultaneous electrochemical determination of hydroquinone, catechol and resorcinol at Nafion/multi-walled carbon nanotubes/carbon dots/multi-walled carbon nanotubes modified glassy carbon electrode", Electrochim. Acta, vol. 149, pp. 237-244, 2014. [http://dx.doi.org/10.1016/j.electacta.2014.10.051]

[13] S.J. Li, Y. Xing, D.H. Deng, M.M. Shi, and P.P. Guan, "A comparative study of different types of reduced graphene oxides as electrochemical sensing platforms for hydroquinone and catechol", $J$. Solid State Electrochem., vol. 19, pp. 861-870, 2015. [http://dx.doi.org/10.1007/s10008-014-2692-8]

[14] G. Marrubini, E. Calleri, T. Coccini, A.F. Castoldi, and L. Manzo, "Direct analysis of phenol, catechol and hydroquinone in human urine by coupled-column HPLC with fluorimetric detection", Chromatographia, vol. 62, pp. 25-31, 2005.

[http://dx.doi.org/10.1365/s10337-005-0570-3]

[15] V.K. Ponnusamy, and J.F. Jen, "A novel graphene nanosheets coated stainless steel fiber for microwave assisted headspace solid phase microextraction of organochlorine pesticides in aqueous samples followed by gas chromatography with electron capture detection", $J$. Chromatogr. A, vol. 1218, no. 39, pp. 6861-6868, 2011. [http://dx.doi.org/10.1016/j.chroma.2011.08.019] [PMID: 21872868]

[16] M.F. Pistonesi, M.S. Di Nezio, M.E. Centurión, M.E. Palomeque, A.G. Lista, and B.S. Fernández Band, "Determination of phenol, resorcinol and hydroquinone in air samples by synchronous fluorescence using partial least-squares (PLS)", Talanta, vol. 69, no. 5, pp. 1265-1268, 2006.

[http://dx.doi.org/10.1016/j.talanta.2005.12.050] [PMID: 18970713]

[17] P. Nagaraja, R.A. Vasantha, and K.R. Sunitha, "A sensitive and selective spectrophotometric estimation of catechol derivatives in pharmaceutical preparations", Talanta, vol. 55, no. 6, pp. 1039-1046, 2001.

[http://dx.doi.org/10.1016/S0039-9140(01)00438-6] [PMID: 1896 8454]

[18] S. Li, X. Li, J. Xu, and X. Wei, "Flow-injection chemiluminescence determination of polyphenols using luminol-NaIO4-gold nanoparticles system", Talanta, vol. 75, no. 1, pp. 32-37, 2008

[http://dx.doi.org/10.1016/j.talanta.2007.10.001] [PMID: 18371843]

[19] S. Feng, Y. Zhang, Y. Zhong, Y. Li, and S. Li, "Simultaneous determination of hydroquinone and catechol using covalent layer-bylayer self-assembly of carboxylated-MWNTs", J. Electroanal. Chem. (Lausanne Switz.), vol. 733, pp. 1-5, 2014.

[http://dx.doi.org/10.1016/j.jelechem.2014.09.019]

[20] H.S. Han, J.M. You, H. Seol, H. Jeong, and S. Jeon, "Electrochemical sensor for hydroquinone and catechol based on electrochemically reduced GO-terthiophene-CNT", Sens. Actuators B Chem., vol. 194 pp. 460-469, 2014.

[http://dx.doi.org/10.1016/j.snb.2014.01.006]

[21] Y. Ni, Z. Xia, and S. Kokot, "A kinetic spectrophotometric method for simultaneous determination of phenol and its three derivatives with the aid of artificial neural network", J. Hazard. Mater., vol. 192, no. 2, pp. 722-729, 2011.

[http://dx.doi.org/10.1016/j.jhazmat.2011.05.081] [PMID: 21719195]

[22] J.G. Manjunatha, B.E. Kumara Swamy, and M. Deraman, "Electrochemical studies of dopamine, ascorbic acid and their simultaneous determination at a poly (Rosaniline) modified carbon paste electrode: A cyclic voltammetric study", Anal.Bioanal.Electrochem., vol. 5, pp. 426-438, 2013.

[23] J.G. Manjunatha, B.E. Kumara Swamy, M. Deraman, and G.P. Mamatha, "Simultaneous voltammetric measurement of ascorbic acid and dopamine at poly (vanillin) modified carbon paste electrode: A cyclic voltammetric study", Pharma Chem., vol. 4, pp. 2489-2497, 2012.

[24] J.G. Manjunatha, M. Deraman, and N.H. Basri, "Electrocatalytic detection of dopamine and uric acid at poly (basic blue b) modified carbon nanotube paste electrode", Asian J. Pharm. Clin. Res, vol. 8, pp. 48-53, 2015.

[25] J.G.G. Manjunatha, "A novel poly (glycine) biosensor towards the detection of indigo carmine: A voltammetric study", J. food Drug Anal., vol. 26, no. 1, pp. 292-299, 2018.

[http://dx.doi.org/10.1016/j.jfda.2017.05.002] [PMID: 29389566]

[26] J.G. Manjunatha, "Electroanalysis of estriol hormone using electrochemical sensor", Sens. Biosensing Res., vol. 16, pp. 79-84, 2017.

[http://dx.doi.org/10.1016/j.sbsr.2017.11.006]

[27] J.G. Manjunatha, "Highly sensitive polymer based sensor for determination of the drug mitoxantrone", J. Surface Sci. Technol, vol. 34, pp. 74-80, 2018

[http://dx.doi.org/10.18311/jsst/2018/15838]

[28] M. Yongjun, J. Zhimei, P. Bo, D. Jing, N. Wang, and M. Zhou, "Investigation of direct electrooxidation behavior of NADH at a chemically modified glassy carbon electrode", J. Electrochem. Soc., vol. 162 , pp. 317-320, 2015 .

[http://dx.doi.org/10.1149/2.0191506jes]

[29] S. Dönmez, F. Arslan, N. Sarı, N. Kurnaz Yetim, and H. Arslan, "Preparation of carbon paste electrodes including poly(styrene) attached glycine-Pt(IV) for amperometric detection of glucose", Biosens. Bioelectron., vol. 54, pp. 146-150, 2014. [http://dx.doi.org/10.1016/j.bios.2013.10.059] [PMID: 24269757]

[30] M. Li, F. Ni, Y. Wang, S. Xu, and D. Zhang, "Sensitive and facile determination of catechol and hydroquinone simultaneously under coexistence of resorcinol with a $\mathrm{Zn} / \mathrm{Al}$ layered double hydroxide film modified glassy carbon electrode", Electroanal, vol. 21, pp. 1521-1526, 2009 [http://dx.doi.org/10.1002/elan.200804573]

[31] J. Peng, and Z.N. Gao, "Influence of micelles on the electrochemical behaviors of catechol and hydroquinone and their simultaneous determination", Anal. Bioanal. Chem., vol. 384, no. 7-8, pp. $1525-1532,2006$ [http://dx.doi.org/10.1007/s00216-006-0329-1] [PMID: 16505984]

[32] P.S.D. Silva, B.C. Gasparini, H.A. Magosso, and A. Spinelli, "Electrochemical Behavior of Hydroquinone and Catechol at a Silsesquioxane-Modified Carbon Paste Electrode", J. Braz. Chem. 
Soc., vol. 24, pp. 695-699, 2013.

[http://dx.doi.org/10.5935/0103-5053.20130079]

[33] F. Hu, S. Chen, C. Wang, R. Yuan, D. Yuan, and C. Wang, "Study on the application of reduced graphene oxide and multiwall carbon nanotubes hybrid materials for simultaneous determination of catechol, hydroquinone, p-cresol and nitrite", Anal. Chim. Acta, vol. 724, pp. 40-46, 2012.

[http://dx.doi.org/10.1016/j.aca.2012.02.037] [PMID: 22483207]

[34] L.A. Alshahrani, X. Li, H. Luo, L. Yang, M. Wang, S. Yan, P. Liu, Y. Yang, and $\mathrm{Q}$. Li, "The simultaneous electrochemical detection of catechol and hydroquinone with $[\mathrm{Cu}(\mathrm{Sal}-\beta-\mathrm{Ala})(3,5-$
DMPz) 2]/SWCNTs/GCE", Sensors (Basel), vol. 14, no. 12, pp. 22274-22284, 2014

[http://dx.doi.org/10.3390/s141222274] [PMID: 25429411]

[35] P.S. Ganesh, and B.E.K. Swamy, "Rekha. Electroanalysis of catechol in presence of hydroquinone at poly (calmagite) modified carbon paste electrode: A voltammetric study", Sci. Lett. J., vol. 5, p. 236, 2016.

[36] W. Si, W. Lei, Y. Zhang, M. Xia, and F. Wang, "Electrodeposition of graphene oxide doped poly(3.4-ethylenedioxythiophene) film and its electrochemical sensing of catechol and hydroquinone", Electrochim. Acta, vol. 85, pp. 295-301, 2012.

[http://dx.doi.org/10.1016/j.electacta.2012.08.099]

\section{2019 Jamballi G. Manjunatha}

This is an open access article distributed under the terms of the Creative Commons Attribution 4.0 International Public License (CC-BY 4.0), a copy of which is available at: https://creativecommons.org/licenses/by/4.0/legalcode. This license permits unrestricted use, distribution, and reproduction in any medium, provided the original author and source are credited. 